\title{
Sustainable Development and Social-Ecological-Technological Systems (SETS): Resilience as a Guiding Principle in the Urban-Industrial Nexus
}

\author{
Klaus Krumme \\ Centre for Logistics \& Traffic (ZLV), University of Duisburg-Essen (UDE), Duisburg, Germany \\ klaus.krumme@uni-due.de
}

\begin{abstract}
This conceptual paper focuses on the connection between system resilience and sustainable development. Setting an inclusive frame and beginning with stating the nature of complexity related to the sustainability challenge and the resultant uncertainty of planning and management within socio-economic domains, the article describes the demand for a system approach and emphasizes the importance of a resilience-oriented approach to sustainable development, including the provision of correlated conceptual frameworks, as opposed to an efficiency paradigm.
\end{abstract}

The first part of the article mirrors on a systematic collection, assessment and reflection of scientific contributions alongside sustainable development/ sustainability strategies, resilience thinking and especially combinations of both with system theory/ nested systems theory, using a qualitative integrative research review method. Sources principally consider progressive explicitly interdisciplinary directions of the scientific community, evolved through the recent decades as sustainability sciences. The scientific state of knowledge is contextualized with subchapters of introduction, problem statement, and demand profile for problem solutions as well as system resilience as point of reference.

The central focus of the second part is on urban and industrial spheres of un-sustainability as well as their functional inter-connectedness as a main potential driver for progress in sustainable development. Elements of rooting sustainable development in a stronger consideration of an urban-industrial nexus proposed here are suggested for a consideration of resilience to describe more appropriate system constitutions and intra-connections as well as better system boundaries for assessments and innovative solutions. For the guiding of a more inclusive view of system agents inside the urban-industrial nexus, expansion of Social-Ecological Systems (SES) towards Social-Ecological-Technological Systems
(SETS) as guiding resilience based framework is proposed. The urban-industrial nexus and SETS are considered as a basis for new research directions of sustainability sciences.

Keywords - Sustainable Development, Sustainability Challenge, System Thinking, Resilience, Systems Integration, Urban-Industrial Nexus, Social-Ecological Systems (SES), Social-Ecological-Technological Systems (SETS), Sustainability Science.

\section{INTRODUCTION}

As an epochal contribution to the future of the world, the international community recently adopted their SDGs, the "Sustainable Development Goals" (Sachs 2015, United Nations 2015). To produce practical and measurable progress towards sustainability, 17 goals have been identified as SDGs covering all critical ecological, social and economical issues corresponding to sustainable development and a number of grand global challenges. Although they differ in an improved level of concreteness, the SDGs stand in the tradition of the former Millennium Development Goals (MDGs) and the Rio Process (Sachs 2012). The aim is to meet concrete objectives -which is of ultimate importance- while at the same time base progress on a safe operating space for humanity, respecting the planetary boundaries (Folke and Rockström 2009, Rockström, Steffen et al. 2009, Rockstrom and Klum 2015, Steffen, Richardson et al. 2015).

The concept of sustainability and the practice oriented directions towards sustainable development have been discussed widely in the academic and nonacademic world from many perspectives, producing different and also partly contradictory baseline understandings (Brundtland, Khalid et al. 1987, Costanza and Patten 1995, Elkington 1997), up to sophisticated scientific discourses about the inner meaning of constitutional frameworks and theories 
(Ayres, van den Berrgh et al. 2001, Ekins, Simon et al. 2003, Neumayer 2003, Dietz and Neumayer 2007) and detailed refinements and advanced conceptualizations (Kay, Regier et al. 1999, Ravetz 2006, Kajikawa 2008, Liu, Mooney et al. 2015, Steffen, Richardson et al. 2015). Apart from numerous understandings and definitions we can identify a consensus in a target orientation stating the "goal of sustainable development is to create and maintain prosperous social, economic and ecological systems" (Folke, Carpenter et al. 2002).

However, the way to achieve this ultimate goal remains untrustworthy and is not based on a deep consensual framework or a resulting sufficient agenda process. This cannot be changed by political conventions alone, but needs deeper conceptualizations on its basis.

The objective of this paper is to serve this need by integrating consolidated scientific fundaments that are able to guide sustainable development concretely and reliably in form of a conceptual framework. A stronger system thinking perspective is favored to explore the beneficial relationship between concepts of sustainability and system resilience. A resilience anchored sustainable development of crucial drivers and functional leverage domains of the socioeconomic sub-systems would be of great advantage to improve the coordinates for sustainable development and to find more appropriate and deeper rooted conceptualizations on the course. In this sense an elaboration on more appropriate system boundaries with respect to integration of crucial and powerful driver spheres of (un-)sustainability would be required. On such a foundation, outlines of guiding frameworks for assessment and development can be prepared or existing ones could be refined and extended. This would represent promising perspectives for those who are committed with a stronger progress for sustainability in science, society, economics and the public policy sector.

\section{METHODOLOGICAL OVERVIEW}

As the basis of the conceptual developments of this article stands a desktop literature review process, based on the methodology of integrative research review (Cooper 1989, Cooper 1998) with the aim of a hermeneutic synopsis of the approaches and findings, the generation of new problem overviews of major problem areas as well as related scientific propositions and solution proposals. According to
Cooper (1989) and Hsia (2015), the review process was executed as a qualitative meta-analysis, oriented on primarily the state of research on sustainability theory, resilience theory as well as both in combination (e.g. in the terms of Social-Ecological Systems frameworks, SES, by Ostrom (2009) and other system-related conceptions), and secondly on the trends in research in the field of sustainability theory, resilience and sustainable development and system theory derived approaches in this context. The review used Thomson Reuters (preferably Web of Science) as well as Elsevier (preferably ScienceDirect) databases under use of EndNote software in facultative consolidation with a Google scholar search. The search mode was restricted to key-terms in the context of sustainability and resilience in peer-reviewed journals with an explicitly visible interdisciplinary chorus of established modern sustainability sciences. Centrally important and metaoriented forums of research publication, such as "Nature", "Science" or "Proceedings of the National Academy of Science (PNAS)", have been considered as far as topic(s) and author(s) are related to the first condition. The accompanying Google scholar search was also considering centrally important and highly cited book and policy paper publications if they stand in a contents connection to the peer-reviewed journal publications of the first instance.

An extensive database of the relevant literature was developed in EndNote software for the further work process. The integrative research review process was consisting of (1) problem and task definition, (2) data collection, (3) summaries and clusters, (4) evaluation of data points, and (5) analysis and interpretation. The integrative research review was then embedded into a conceptual framework and theory building process adopted on the basis provided by Meredith (1993) and Wacker (2008). The conceptualization phase is an iterative process involving extensive reading, additional collection of literature, synthesis, and refinement of the framework via structured discussions with scientific scholar groups over a period of 15 months (under additional use of shared EndNote resource groups).

Within the scope of this paper, literature findings and synthesis of the state of research are contextualized in a first step with the subchapters of introduction, problem statement, demand profile for problem solutions as well as system resilience as point of reference, considering specific propositions and demands according to the suggestions of Wacker 
(2008). In a second step trends in research in coherence with state of research are developed as logical deduction into the conceptual chapters of the urban-industrial nexus and the social-ecologicaltechnological systems (SETS), principally oriented to Handfield and Melnyk (1998).

In accordance with Meredith (1993), this paper provides elaborations on conceptual frameworks, presented in text explanations and conceptual figures on the fundament of a number of interrelated scientific propositions which explain phenomena and/ or provide understanding of un-sustainability, sustainability/ sustainable development, system resilience, social-ecological/ economic-ecological interactions as well as sustainable economics/ ecological economics. The methodology to accomplish then conceptual frameworks and model building consists of an integration of a number of different journal contributions, summariz(ing) the common elements, contrast(ing) the differences, and extend(ing) the work in some manner (Meredith 1993).

\section{CONCEPTUAL PROBLEMS COPING WITH THE SUSTAINABILITY CHALLENGE}

Apart from complicated and counterproductive disagreements and unconsolidated ambitions in the political and economic arena, as characterized amongst others by Sachs (2016), the author can put forward three fundamental interrelated obstacles on the way towards sustainable development course corrections related to the status of research and practice:

- The academic world still shows divergent perceptions and itself has unconsolidated knowledge about sustainability as well as counter-productive self-conceptions still depending on disciplinary ways of thinking and research (Lawrence 2015, Wilkinson, Horwitz et al. 2015, Alder 2016). Sustainability Science as a newer and more inclusive school of academic acting based on post-normal science (PNS) (Ravetz 1987, Funtowicz and Ravetz 1995) is still no mainstream in the academia and needs to become much stronger. The actual ineffectiveness of the traditional science system was already maturely described and is more striking the more complex the societal challenge gets (Funtowicz and Ravetz 2003, Ravetz 2006,
Kläy, Zimmermann et al. 2015).

- Practical implementation in economics/ industrial, technological and social sectors suffers from the first obstacle and itself shows no "applied" approach to create really fundamental course corrections and radical alternatives within and across sectors to improve their performances towards sustainability (Shrivastava 1995, Tonelli, Evans et al. 2013, Whiteman, Walker et al. 2013).

- Beside the inappropriate non-consolidated or totally missing common referential background of respective actor groups, a low operationalization potential even of recognized references, irritated by supposedly blurred or misperceived concepts of sustainability, hinder a stronger but urgently needed progress in understanding, action and monitoring for sustainability (Dietz and Neumayer 2007, Neumayer 2012, Davies 2013, Barkemeyer, Holt et al. 2014).

The above obstacles are inherently connected to stakeholder groups, their explicit knowledge stocks, mindsets and abilities do correspond with the overriding complexity of the sustainability challenge itself: The economic, social and ecological dimensions of reality come out as closely coupled in their actual performances. Principally we have moved away from the bounded, controllable scope of traditional products and services to rather boundaryless, erratic realms of industrial, ecological and social system interrelationships (Fiksel 2006). Climate change, urbanization, resource scarcity, and the causal dynamic texture of a globalized industrial economy are intermediate snapshots of a multifaceted regime shift, but do generate further regime shifts in highly complex cascades and on various levels and scales of the social, ecological and economical organization of a transformed planet (Folke and Rockström 2009, Hughes, Carpenter et al. 2013, Hoekstra and Wiedmann 2014, Steffen, Richardson et al. 2015). Each particular course of socio-economic developments (e.g. expansion of cities, course of industrial branches, transition in energy supply), as parts of this complexity, is in conclusion highly volatile. It is noteworthy to understand that the widespread understanding of sustainability in terms of the "people, planet, profit" bottom line (Elkington 1997) or the politically accented Brundtland-Definition of inter- and intra-generational justice (Brundtland, Khalid et al. 
1987) use social, economical and ecological spheres as reductionist categories and at last superficial perceptions of a much more complex reality. The politically influenced reductionist approaches on sustainability helped to introduce a new way of thinking and made sustainability quite popular, but are not helpful to cope afterwards and consequently with the underlying complexity of the challenge as well as to operationalize strategies in and across sectors of our socio-economic system.

In an effort to structure root causes of un-sustainability we can identify that human pressures on the planet are strongly associated with the global duality of urbanization and industrial backgrounds in a functional amalgamation (Seto and Satterthwaite 2010, Ahern 2011, Liu, Mooney et al. 2015). Accordingly, both sustainable urban development (SUD) and green economy play central roles in the discussion on global sustainability transitions (Bugliarello 2006, Jänicke 2012). In both directions of discourse, the cross-cutting energy transition away from massive use of fossil resources towards renewable energy resources and closing of supply loops is a central agenda issue (Heinberg 2004, Atkinson 2007, Kaygusuz 2012, Twidell and Weir 2015). Taking up the overstretched capacity of the global climate system and its tipping points for risky regime shifts of the system and its ecological and socio-economic interconnections, a really fast progress towards a renewable based industrial economy is now the decisive step (De Vries, Van Vuuren et al. 2007, Schellnhuber and Martin 2014, Galil 2015). As Negro, Alkemade et al. (2012) indicate, the transition process shows dangerously slow pace. Following Dangerman and Schellnhuber (2013), the slow pace of necessary change as well as some backfiring against sustainable solutions also belong to complex nature of systems and can be explained as a powerful dynamic locked-in effect, described by Senge (1990).

\section{A DEMAND PROFILE FOR SYSTEM ALTERNATIVES AND ALTERNATIVE SYSTEMS}

The building of sustainable systems in the sense of integrating highly complex interplays of unsustainable domains is still ineffective and should be taken as a major motivation for progress in sustainability sciences (Clark and Dickson 2003, Fiksel 2006, Kerkhoff 2013). Practically it becomes unfeasible to execute autonomous assessments and planning for sustainability in a particular industry or a social sector without being confronted with broader repercussions in manifold functionally contiguous sectors (Fiksel 2006). It will become necessary to relate countermeasures and alternative solutions to the actual status quo of existing sectors in economical/ industrial or social life to transform current settings into new and better arrangements.

To effectively overcome the above described disadvantages, affected stakeholders have to intentionally mirror the complexity of real world systems in the achieved assessments and alternative countermeasures for sustainable development. Bearing in mind the above statements, the author can recapitulate as a first step for a profile of system alternatives and alternative systems demands enumerated hereunder:

- Academic as well as practical expertise need a more consolidated referential knowledge background of sustainability science, a solid basis on which interfaces can jointly be operated on in the sense of post-normal science (PNS). This background must encompass a system understanding of problem(s) and their dynamics as well as a systemic approach of connecting alternatives, improvements and innovations in its system complexity.

- Stakeholders have to understand that course corrections in their effectiveness do depend on often counterproductive system effects that could hinder better solutions even if better knowledge is available. Counterproductive conservative structures can very successfully hinder progress through power and inherent counterforce against change in systems, even if this leads to false solutions or a down pacing of needed progress.

- Ultimate drivers of a system transition such as corresponding urbanization and industrialization should be explored in their systemic interconnectedness as strong solution drivers in an integrated way instead of using reductionist categories of actually systemically interrelated social, economic and ecological spheres. A stronger focus on urban-industrial drivers treats them as nuclei of change through leverage functions into other systemically related transformation fields. 
To perceive problems correctly in their comprehensiveness and to cope with complexity, system thinking is a possible prerequisite. In a systems thinking approach the investigated entities and their environment are interpreted from a systemic viewpoint, starting with the analysis of fundamental elements and finally considering more complex related systems (Bertalanffy 1950, Bertalanffy 1968). Each entity is seen as a (sub-)system in its relationship to other systems, placed at higher levels of observation. The features of this "system of systems" can be detected in sub-systems and is described as principles of nested systems hierarchies or nested systems organization (Bossel 2007). The principle unit of analysis is a system made up of multiple compartments, structures and processes that can be described as functions or 'services' within the system (Odum and Barrett 1971). Figure 1 introduces central termini of the nested systems theory.
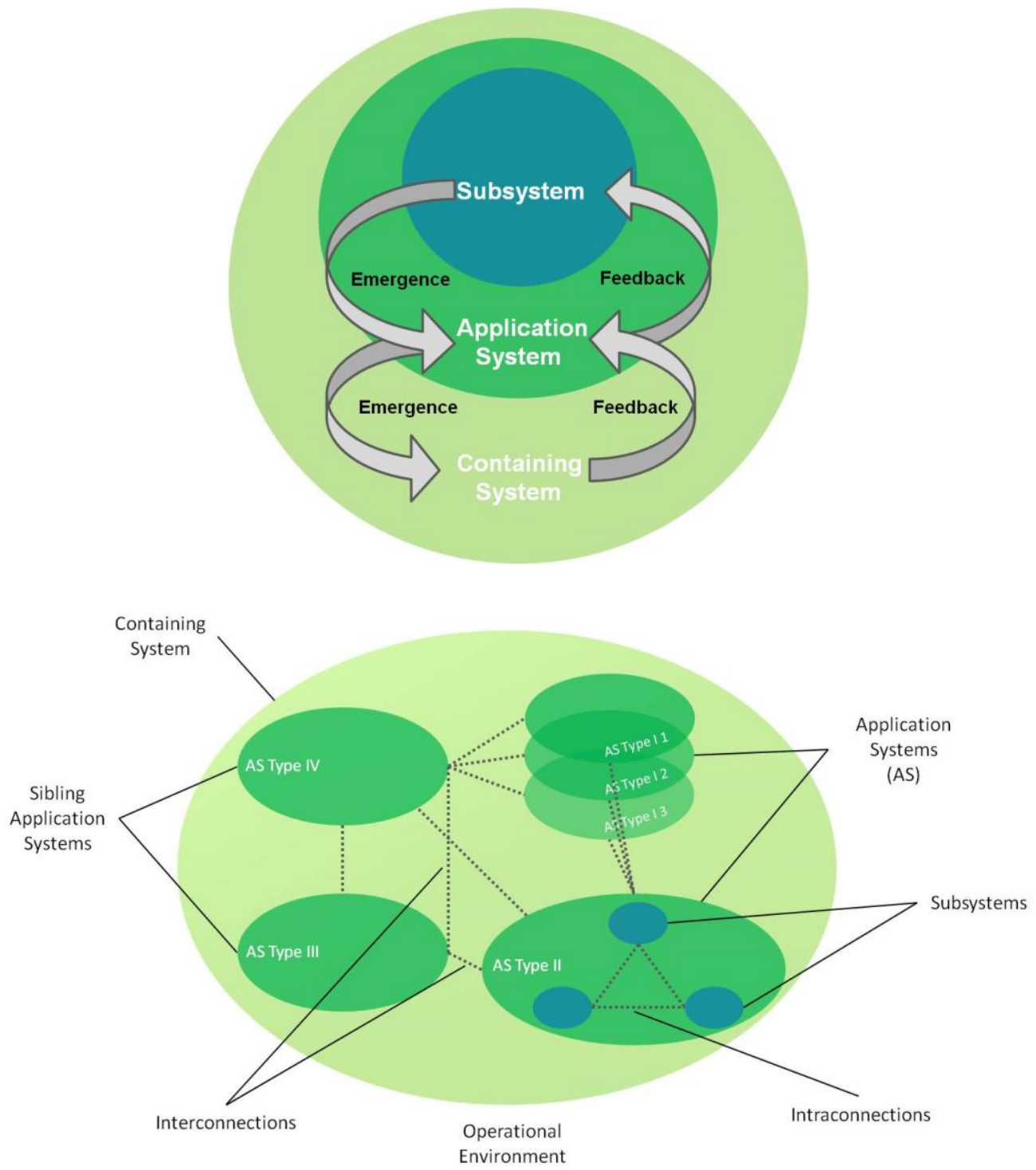

Fig .1. Nested Systems Hierarchies (a)/ Nested Systems Organization (b)

Beyond the analytical perspectives on the system status and system organization, concrete alternative system-oriented management approaches and setting of new integrated systemic frames upon decisions and actions on sustainable development are obligatory (Korhonen and Seager 2008, Wiek, Farioli et al. 2012, Miller, Wiek et al. 2014). To reach this goal, institutions have to effectively balance their demands 
and need to be enabled to cope with uncertainty as a result of complexity (Fiksel 2006, Fiksel 2015). In line with Joseph Fiksel we can identify central questions in concern of a performance demand profile for future socio-economic systems, as enumerated below:

- How can socio-economic systems achieve long and short-term economic success AND long term social stability AND productivity AND long term ecological integrity under changing conditions of the greater system environment?

- What solutions can science provide to better understand the interlinked behaviours and emerging risks as well as opportunities of complex social, economic and ecological subsystems contained in bigger system operation orders?

- How can this be applied to design and management of institutional as well as technological, infrastructural and managerial systems to meet societal demands, especially in the cross-sector of (renewable) energy as a conditioning factor for the sustainability performance?

\section{SYSTEM RESILIENCE AS POINT OF REFERENCE FOR SOLUTION DESIGNS}

To operationalize the demand profile we can learn from the complex system behaviour of natural ecosystems emerged through millions of years of (co-) evolutionary processes of the systems, their compartments and nested levels of mutual organization. A central ability and furthermore an organizational principle of natural systems to adapt its functionality and structures dynamically against interference is described as system resilience, or simple: resilience. Resilience of a system counts on compartments ("agents") and their interrelations to entirely emerge sustainability, literally as durability or survival of the system in a dynamic surrounding of subtle or sudden change.

This view assumes natural systems as an interesting model for the above described demands. The observation of natural ecosystems shows that not only transient shocks lead to a destabilization of systems, but also chronic stress, slow and subtly changing conditions, can play an important role (Rapport 1995). Both are true for factors and processes referred to unsustainability. The description of system resilience has its scientific origin in the early 1970s (Holling 1973).
The concept has undergone some refinements, but a contemporary definition concentrates on conditions for multiple flexible equilibriums. Resilience commonly refers to ".... the magnitude of disturbance that can be absorbed before the system changes its structure by changing the variables and processes that control its behaviour" (Gunderson 2000). In addition to these notions of resilience, further interlinked core aspects are given, including the extent to which the system is capable of self-organization (Perrings and Walker 2004) as well as its ability to build and increase capacity for learning and adaptation (Folke, Carpenter et al. 2010). This understanding of resilience is still unwieldy to operationalize for sustainable development. A more applicable detailing of the resilience concept was delivered by Walker, Holling et al. (2004). The state of systems is considered in four dimensions:

- latitude - width of the "basin of attraction" in which the system is able to operate

- resistance - difficulty of changing the system

- precariousness - how close is the trajectory of the system to a threshold

- cross-scale relations (panarchy) - how much are other attributes affected by sub-systems

In simple terms system resilience can be illustrated with a ball in a basin. An interference or disturbance of the system leads to a more or less powerful displacement and motion of the ball. Normally the ball will return into a stable equilibrium in the middle of the basin after a disturbance. Resilience is determined by the width and depth of the basin, so that the system would lose its original properties when the ball is moved over basin rim, indicating the exceeding of thresholds and the following tipping points of system stability (figure 2). So both the intensity of stress or disturbance on a system and the lowering or elevation of its thresholds (system properties, displayed as structures, functions or services) has influence on the system resilience.

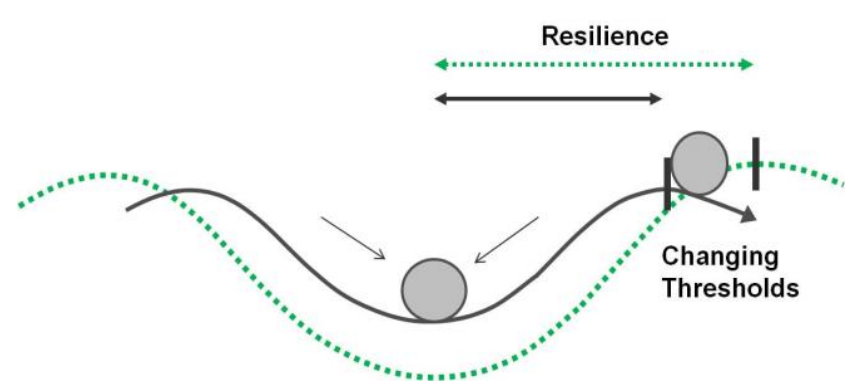

Fig .2. Illustration of System Resilience (Source: Stockholm Resilience Centre, modified) 
It is striking how much this can be transferred to socio-economical, socio-technological and industrial systems and their ultimate dependence on an ecological meta-system. Resilience design is driven by the need for flexible adaptation and insight into limited forecasting capacities and non-linear behaviour of complex dynamic systems. With help of the above four dimensions of system state, referred to as "capacities", first qualitative or even quantitative descriptions of resilience can be specified and practicable design options to enforce abilities to learn and to innovate (self-) repair capacities as forms of adaptation can be derived.

Crucial for adaptive capacity is the broadening and diversification of the resource base of desired sustainable systems. The diversity and presence of multiple and also redundant elementary structures, as reserves or buffers, ensure ancillary services, even if conditions change drastically and/or if key elements fail (Folke, Carpenter et al. 2002, Folke, Carpenter et al. 2010, Brown and Williams 2015). This is the main reason why from a system thinking view, strategies of pure eco-efficiency do not lead to sustainable improvements (Korhonen and Seager 2008, Fiksel 2015, Korhonen and Snäkin 2015). Simply lean and energetically optimized resource systems, for example in industrial or urban contexts, cannot meet needed flexibility and adaptability in terms of an "in vivo" fluctuating environment. In the longer term they may be inefficient due to lower long term persistence in their economic performance and thus bring new risks and additional costs.

The way how agents and interrelationships are organized is decisive for emergence of system resilience against internal and external disruptions. Taking this perspective, resilience can be more interpreted in terms of conserving functions than cementing structures. In our context, an ultimate meaning to achieve this would have functional integration of agents belonging to social, economical and ecological dimensions and include their levels of interconnectedness into our strategy. However, a resilience perspective is significantly connected to understanding of dynamics and to plan and manage within social-ecological systems (SES) (Folke 2006, Walker, Gunderson et al. 2006) as well as for dynamics of ecological-economic systems (Derissen, Quaas et al. 2011, Chopra and Khanna 2014). In this context, a focus is on adaptive management and governance as a linking momentum between the socio-economic and the ecological sub-systems in concern of ecosystem goods and services (ESGS) (Costanza, d'Arge et al. 1997, De Groot, Wilson et al. 2002, de Groot, Alkemade et al. 2010) provided by the ecological system part and the management systems for resource use by institutions/ organizations determined by the socio-economic part (compare figure 3).

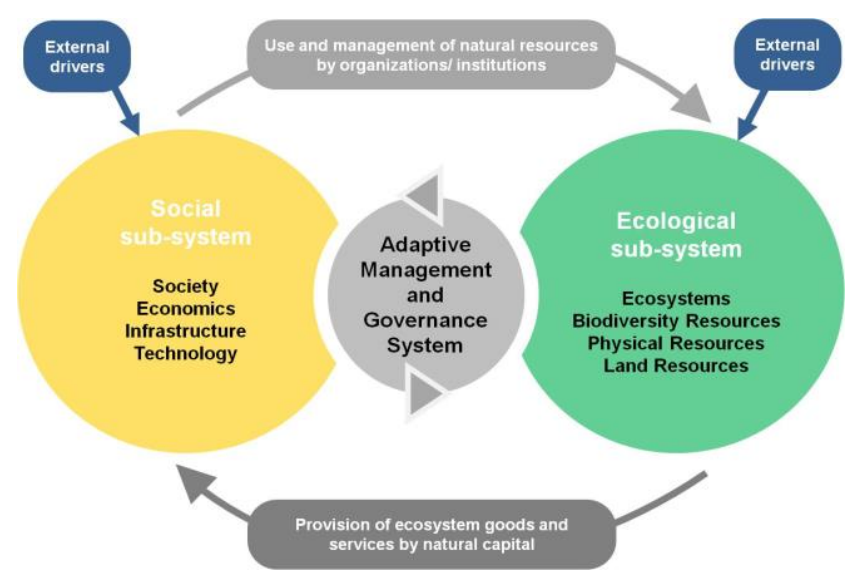

Fig .3. Resilience through Adaptive Management and Governance in SES, after Ostrom (2009), strongly modified

To some extent the notion of resilience at more practice oriented policy interfaces, even in international organizations, often remains disproportionally restricted to efforts enforcing physical infrastructure resilience in light of climate change impacts; see e.g. UNISDR (2012). Although this is an important field, it is essential to note that a truly resilience guided strategy of generally anthropogenic, specifically socio-economic subsystems, would address more fundamental skills, essentially related to social networks to reconfigure, establish or maintain infrastructures (Hahn, Schultz et al. 2008, Cote and Nightingale 2012, Bahadur, Ibrahim et al. 2013). It is important to be aware that compensation capabilities in response to uncertainties derive from the behaviour of the stakeholders (individual or as organizational entity) as structural and dynamic properties of the system.

A system needs to be open to learning as a main prerequisite for dynamic knowledge stocks, adaptation policies and intervention strategies, to reorganize structural elements, innovating social and ecological components and - in the end - keep up their key functions as ultimate purposes of the system independent from original infrastructural settings. Therefore, institutions need to be open and flexible in 
order to allow continuity in working and learning and consequently support an increase in their adaptive capacity. Thomas and Twyman (2005) as well as Bahadur, Ibrahim et al. (2013) consider decentralization, equity, justice and social diversity as key issues for effective governance for sustainability. Decentralization can lead to management and decision making structures, which are closer to specific needs of communities. So decisions made can be robust, reliable and long-term. Also in case of an upcoming crisis in a decentralized system the breakdown of one authority will probably not lead to a collapse of the entire system.

On the whole, the author states that with regard of SES, resilience is addressed to a spectrum of subsystems and organizational layers within systems.
Consequently specific organizational concreteness for the social-cultural sub-system (with norms, values, mindsets, etc.), the ecological sub-system (resource base, ecosystem services, carrying capacities and thresholds, etc.), the institutional frames (learning, flexible organizational forms, etc.), important interfaces of the social and the ecological as well as technological assets (maintenance, supply-demand relations, services, etc.), infrastructure (redundancy, reliability, response capacity, etc.) or management and engineering (flexibility, modularity, collaborative solutions, user integration, etc.) can be articulated. This can help to built up better and more structured approaches to implement resilience design strategies in specific work fields of sustainable development (figure 4).

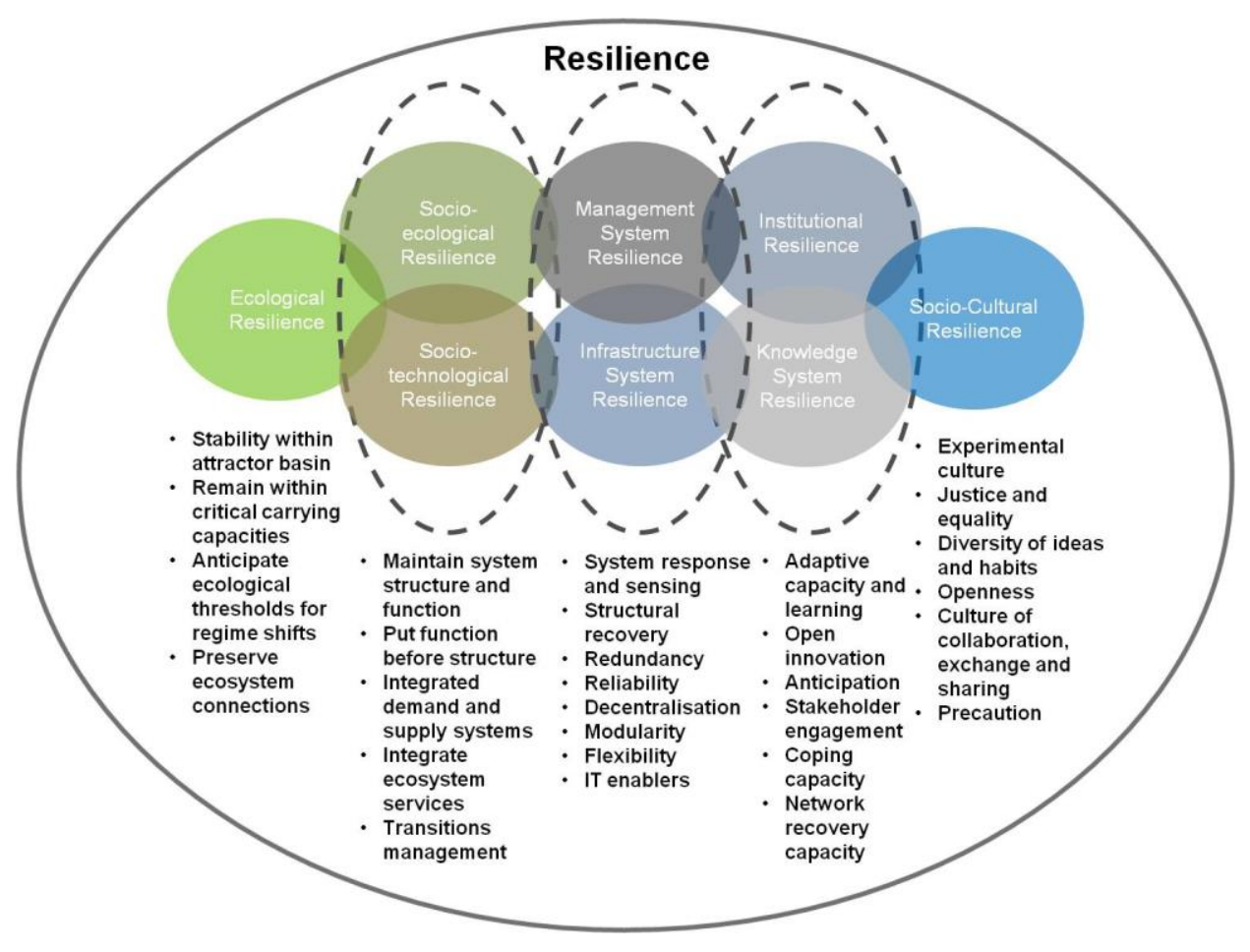

Fig .4. Resilience Design in ecological and socio-economic sub-systems

For the entirety of an observed system and for each sub-system or interface the following four system aspects/ properties play conditioning and crossoriented roles in resilience design:

- System resources and system agents comprehensiveness and diversity, relating to buffers, alternatives and stocks

- System structures and boundaries to encompass driving functions for a long term viability
- System dynamics defining interactions as balancing, enforcing or attenuating feedbacks

- System capabilities as (re-)configurability of the system dynamics on the basis of stakeholders and institutions and their adaptive capacities

Section 6 will be devoted to a necessary systems integration of (a) resources and (b) structures to ensure basic meta-strategies comprehensive enough for long term viability. This is considered as presuming 
for active system configurability and the potentials to generate sustainable dynamics and capabilities of and within systems. Section 7 will thereafter outline framework constitutions to portray (c) dynamics and to plan and manage those dynamics to positively influence (d) system capabilities.

\section{SYSTEMS INTEGRATION: EXPLORING THE URBAN-INDUSTRIAL NEXUS}

Before taking concrete resilience based development strategies into account, a crucial step in the definition of the application system is answering the questions:

- What is part of the system, and what is not?

- On which nested organizational layers are parts/ agents operating with which consequence for the emerging performance?

- What are driving or critical or determining (sub-) structures and agents?

- And in which boundaries is their interrelationship effectively situated?

The difficulty where an observed system shows practicable system boundaries depends on the one hand if it is "complete enough" to follow a specific purpose under a given level of complexity, and on the other, to find manageable/planable units and interconnections. Both determine success or failure of efforts for sustainable development. The concrete result of such a selection process may differ in specific contexts on micro- or meso-scales, but more important some fundamental strategic propositions for the macro-scale have to be met in a first instance.

Specifying the operational context of sustainable development, beside many particular (sub-)sectors (agriculture, transport systems, fishery, water management, etc.) literature can be detected purposely on resilience guided sustainable development of urban systems as well as of industrial systems as two core drivers causing global unsustainability. For urban systems, Ahern and colleagues (Ahern 2012, Ahern, Cilliers et al. 2014) promote five strategies to build resilience capacity and a trans-disciplinary collaboration is proposed, concerning biodiversity, urban ecological networks and connectivity, multi-functionality, redundancy and modularization as well as adaptive design in and of urban systems. In the industrial context others are exemplifying the efficiency vs. resilience question on the basis of comprehensive value chains and material flow networks of and in-between firms considering sourcing, production, distribution and consumption sub-structures of supply chains (Zhu and Ruth 2013, Chopra and Khanna 2014) and derive new policy recommendations rooted in industrial ecology (Deutz and loppolo 2015).

The synthesis of functionally highly interrelated aspects as urban-industrial nexus is still missing, although further systems integration of in fact inseparable forces for (un-)sustainability is considered highly necessary (Liu, Mooney et al. 2015) and obvious for industrial and urban spheres. The reason for this misperception might still be a foreground attention to the physical appearance of (infra-) structures of typically urban- or industrial phenotypes. Apart from conventional sectoral thinking a demandsupply rationale, respectively source-sink relationships, makes the interdependency of the two areas understandable: The overshoot of the planet's ecological capacity can be specified in terms of a drastic resource overconsumption of resources at sinks, already causing acute or predictable scarcity at sources on regional or global scale, and by overstretching carrying capacities of the global system (eco-capacity: the ability to absorb or to assimilate caused disturbances), e.g. by destabilizing the global climate (Rockström, Steffen et al. 2009, Barnosky, Hadly et al. 2012, Hoekstra and Wiedmann 2014, Rockstrom and Klum 2015, Steffen, Richardson et al. 2015). Urban systems are the main drivers of this impact and are systematically connected within a complex nexus of sources and sinks of materials and energy. The drastic disproportional impact of urban systems on the global eco-capacity has been illustrated through the application of ecological footprinting methodology to complex urban agglomerations (Rees and Wackernagel 1996, Rees 1997, Rees 2001, Wackernagel, Kitzes et al. 2006). While currently urban areas represent some two percent of the earth surface and inhabit slightly more than 50 percent of the global human population, they consume approximately 70 percent of natural resources and are responsible for roughly 80 percent of the global greenhouse gas emissions (Girardet 2000, Marchal, Dellink et al. 2011). Thus, urbanization needs to be considered as a key for understanding and solution of interlinked demand and supply 
problems in the era of global environmental change. Therefore, it is necessary to make changes in perceptions of cities including their supply systems and critical dependencies and shift the planning and management system boundaries beyond the conventional urban form and structure towards functional sources and sinks pattern in urbanindustrial nexus considerations. Sources would then incorporate not only typical industrial capacities but also those capacities which are sources for the sources in form of ecological resources and/ or ecosystem goods and services ("industrial production as consumption of natural capital") for the background of ecological economics (Costanza, Daly et al. 1992, Rees 2003, Wiedmann, Minx et al. 2006). Sources could better be described as eco-industrial sources to make clearer that sourcing at the ecological resource and ecosystem goods and services play an important role for the further processing in industrial production on the way towards mainly urban sinks.

This shift towards intersectoral approaches across the traditional sector borders is a logical consequence of the earlier introduced system thinking approach. It is necessary to integrate production, demand and supply systems from a 'system of systems' perspective. System thinking provides methodological and structured approaches due to its ability to consider sub-system layers as well as the operational environments within the larger system in forms of nested organizations (Bossel 1987) and supports capturing the dynamic, complex and interdependent nature of the connected (sub-)systems (Sterman 2000).

The urban-industrial nexus represents a shift from a structural or spatial towards a more functional reception of boundaries to reveal the conceptual inseparability of the two drivers for sustainability. Helpful aspects of such an integrated functional viewpoint are the definition of concrete functional domains of supply to link up eco-industrial sources with urban consumption sinks within the urbanindustrial nexus. Those functional domains could be characterized by concepts of supply chain management (SCM) in terms of (a) operations and service levels (plan, source, make, deliver, use, recycle) to perform the supply function and by the dynamics of (b) material and non-material resource flows (resources, goods, commodities, energy, information and value) along the structures of a supply chain. Additionally, (c) supporting typological factors of functional interrelationships (conditioning, trigger, limiting and integrating factors) describe the quality of the relationship between source and sink to serve sustainability of the respective systems (Krumme 2006). Figure 5 shows principle compartments and relationships consisting of resource level, operations level and factors level between the eco-industrial and urban sub-systems.

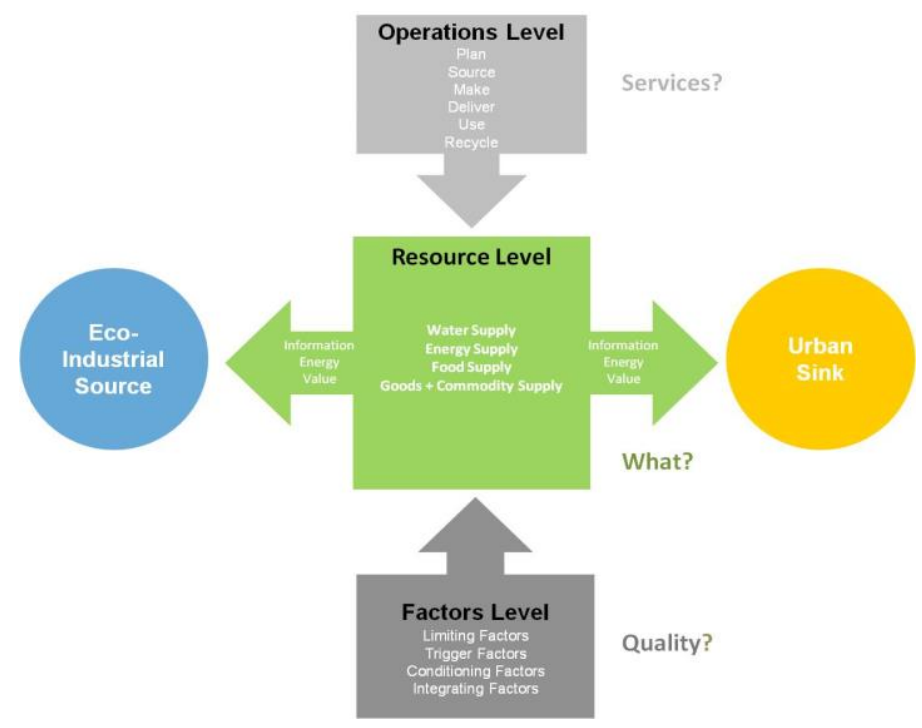

Fig .5. Elements of Urban-Industrial Functional Domains of Supply 


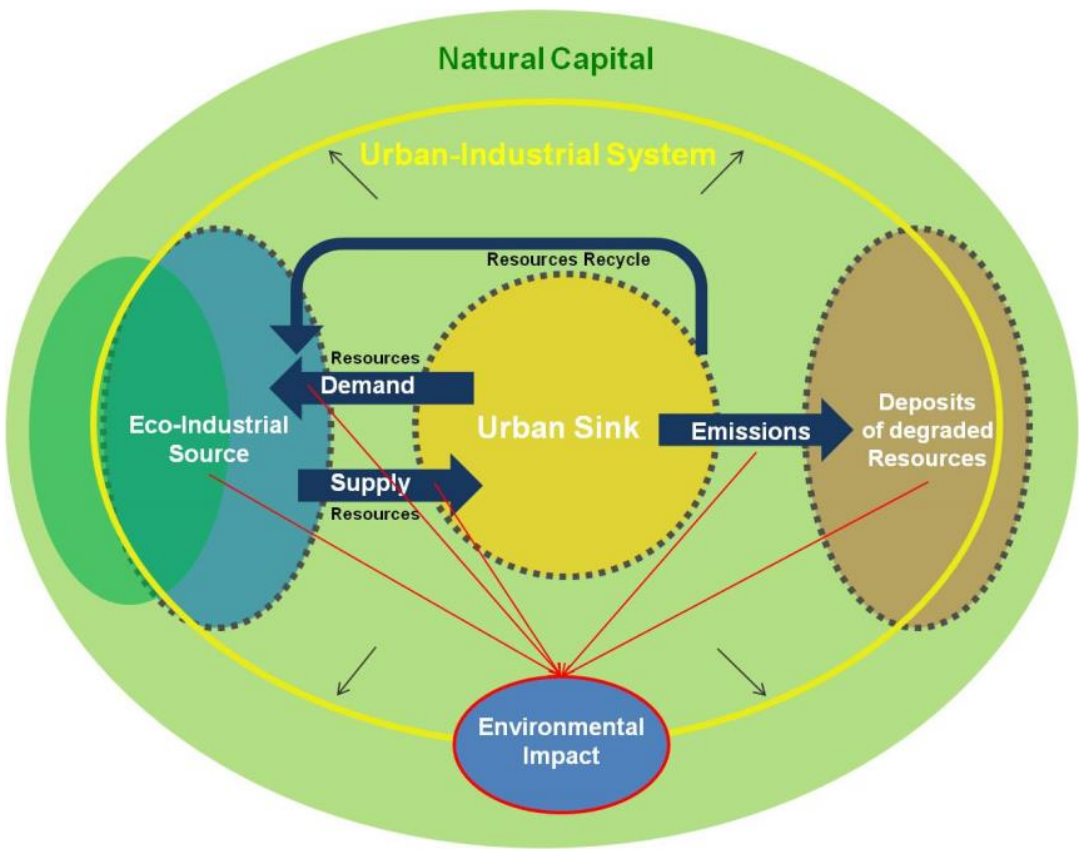

Fig .6. Advanced Ecological Economics Urban-Industrial System Metabolism Model

Once the relationship between eco-industrial source and urban sink is qualified by description of functional domains, the relationship can be embedded into a more comprehensive functional metabolism model in an approach of ecological economics and industrial ecology. Figure 6 shows a non-spatial urban-industrial system metabolism model as a consequence of the functional view of source-sink relations: The urbanindustrial system is described as an expanding unit within the finite surrounding system of natural capital. The expansion is driven by both demand and supply between source and sink. The environmental impact is inclusively driven by supply and demand combined with turnover of resources, the effects on the ecoindustrial source (in terms of conversion of natural capital into human or industrial capital), all kind of emissions on which the urban sink signs responsible for, and non-recyclable deposits of degraded resources if only a part of resource turnover can be redirected in form of a closed loop towards the ecoindustrial source.

Planning and management of an urban-industrial system in a resilient and sustainable manner would consider all system compartments and interrelationships against the background of resilience design. It primarily addresses the multifold factors of the expansion function and of the environmental impact function in an integrated way to reduce both functions under the thresholds of the carrying capacity of the finite natural system. In parallel an increase of the closed loop function between the two sub-systems would be enforced. The establishment of a more integrative system boundary and consideration of interrelated structures as shown in figure 6 and the quality of their relationships demonstrated in figure 5 represent a first ultimate step towards a resilience orientation. Furthermore, it provides several supplementary directions for methodological improvement of the proposed basic functional model.

Such a new perspective directs itself to Jay Forrester's urban and industrial dynamics (Forrester 1961, Forrester 1969, Forrester 1997), basic operations research such as the Viable System Model (VSM) by Stafford Beer (1984) and some recently established links of VSM to sustainability science (Panagiotakopoulos, Espinosa et al. 2016), bioeconomics and thermodynamic receptions of ecological-economic resource systems (GeorgescuRoegen 1975, Georgescu-Roegen 1993) or even ecological footprint methods (Rees and Wackernagel 1996, Wackernagel, Kitzes et al. 2006). All these provide a meta-perspective of nested system organizations beyond a classical sectors view and apart from foreground phenotypic structural perceptions. In terms of first outlines of understanding the language of system dynamics methodology could be appropriate to approach more complex and dynamic levels of functionalities in the urban-industrial nexus. 
After initial steps for systems integration of resources and structures, as the first two of four main system aspects of resilience design (section 5) could be demonstrated, the next section adds dynamics and capabilities and integrates all four system resilience design aspects together in a final illustrated model contextualized with an advanced resilience framework on the basis of the earlier presented SES (figure 3).

\section{FRAMEWORK FOR RESILIENCE GUIDANCE: SOCIAL-ECOLOGICAL- TECHNOLOGICAL SYSTEMS (SETS)}

Resilience orientation makes clear that sustainability as a steady state is impracticable. Sustainability refers to dynamics of interrelated (sub-)systems to emerge a variety of response forms of systems and their agents in multiple and alternative equilibriums within dynamic environments, evident in the behaviour of natural ecosystems. As natural systems a socio-economic system, or in the context of this article an urbanindustrial system in a more specific focus, depends in its ability to adapt to changing conditions (adaptability) on different system capabilities (based on fundamental distinct capacities) that can be actively or passively developed, can flourish or being deteriorated. Therefore, against the backdrop of resilience design, system dynamics and system capabilities stand in a significant affiliation to each other.

Building on the system-theoretical background of system ecology with the goal of resilience, the researcher can interpret technological, economic, social and environmental factors of urban-industrial systems as interoperable compartments of a dynamic network equilibrium that considers all system compartments as an "ecosystem" building up system capabilities as characteristic properties. Resilience as a guiding concept allows us encompassing and systematizing the relevant key performance factors for sustainable operations in the networked and nested order of urban-industrial systems.

As mentioned earlier, resilience oriented sustainable development strategies point out on inner control and steering mechanisms of social-ecological systems (SES) (see figure 3). Elinor Ostrom convincingly elaborated SES as guiding frameworks (Ostrom 2007, Ostrom 2009, McGinnis and Ostrom 2012) and initiated a new direction of further works on the synthesis of sustainability, resilience and SES (Xu, Marinova et al. 2014) up into strategic and operational spheres of trans-disciplinarity (Binder, AbsengerHelmli et al. 2015). In order to move forward the general perception of sustainable development frameworks, science is recently about to come up with an integration of the technological sphere into SES as social-ecological-technological systems (SETS), particularly for sustainable urban development (Krumme 2016, McPhearson, Pickett et al. 2016). Technology was seen before as a compartment of the social sub-system of SES. In terms of guiding frameworks for sustainable development of strongly artificially transformed environments, such as infrastructures in urban or industrial systems, the question about the transformative capacity of technology and its contribution to socio-economic system capabilities arises more strongly. It seems obvious but still poorly reflected that technology plays a determining role in the functional contexts of the urban-industrial nexus and its significance for (un) sustainability. The question is how the role of technology in modern societies and respectively for sustainable systems driven by the society institutions and organizations can more precisely be described.

It is useful to go back to the original meaning of technology, which comes from the Greek word tekhnologia as "systematic treatment" and from tekhnē as "art" or "skill". If we take into account that the human species' use of technology began with the conversion of natural resources into simple tools, it becomes significant how much the human ability to control and adapt to the natural environments is affected and driven by technology. In this context, technology can also describe a more comprehensive frame of methods, processes, materials, machines, tools and techniques and can be considered an 'enabler' on the interface of social organizations and their environment to facilitate the capture, distribution and repeatable application of value creating knowledge (DeSanctis and Poole 1994, Earl 2001) (figure 7).

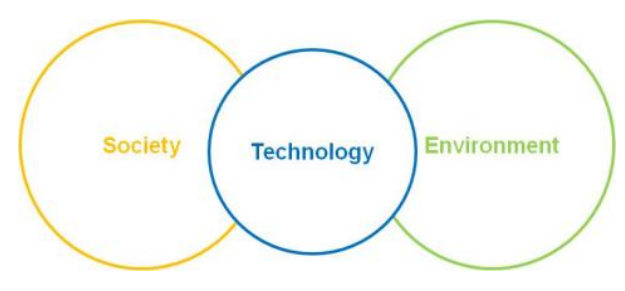

Fig .7. Technology in a sustainability context

As illustrated below, such a comprehensive understanding of technology makes the depiction of dynamics for sustainable development frameworks 
more complete and accents further design options to strengthen resilience (figure 8). The presented illustrated model puts the dynamics of SETS on a platform of the four cross-oriented resilience design system aspects. A number of attributes correlated to four resilience design elements exemplifies the affecting of environmental, social and (new) organizational-technological capacities and their determining sub-systems in SETS. The inner arena shows the dynamics of SETS, oriented on visualization by Hahn, Schultz et al. (2008) for fundamental SES, complemented with a new technological sub-system against the background of the above made explanations. Including the new technological dimension a SETS comprises of ecosystems as natural capital being managed and used by stakeholders and their institutions. This central interplay between humans and natural environment is enabled by a technological sphere in terms of a broad understanding of instruments, processes and methods as explained above. The management and governance systems provide frameworks with which technology is contextualized. The way of management operations is itself influenced by societal norms and values.

The system resilience against external drivers of change of such a SETS imagination depends essentially on carrying capacities of the ecosystem base as well as capacities of institutions and organizations. The way how this bilateral relationship works is enabled by adapted forms of technology and infrastructure on the interface between the social institutions and their management systems as well as the ecological functions of natural capital. Technology, therefore, plays a role as enabler of operational management modes and specific operations being more or less sustainable. A conditioning factor for the described interplay is fulfilled by progress in knowledge and competence capacities that are able to transform institutional as well as management assets of the system and, more subtle, also values and norms (and vice versa).

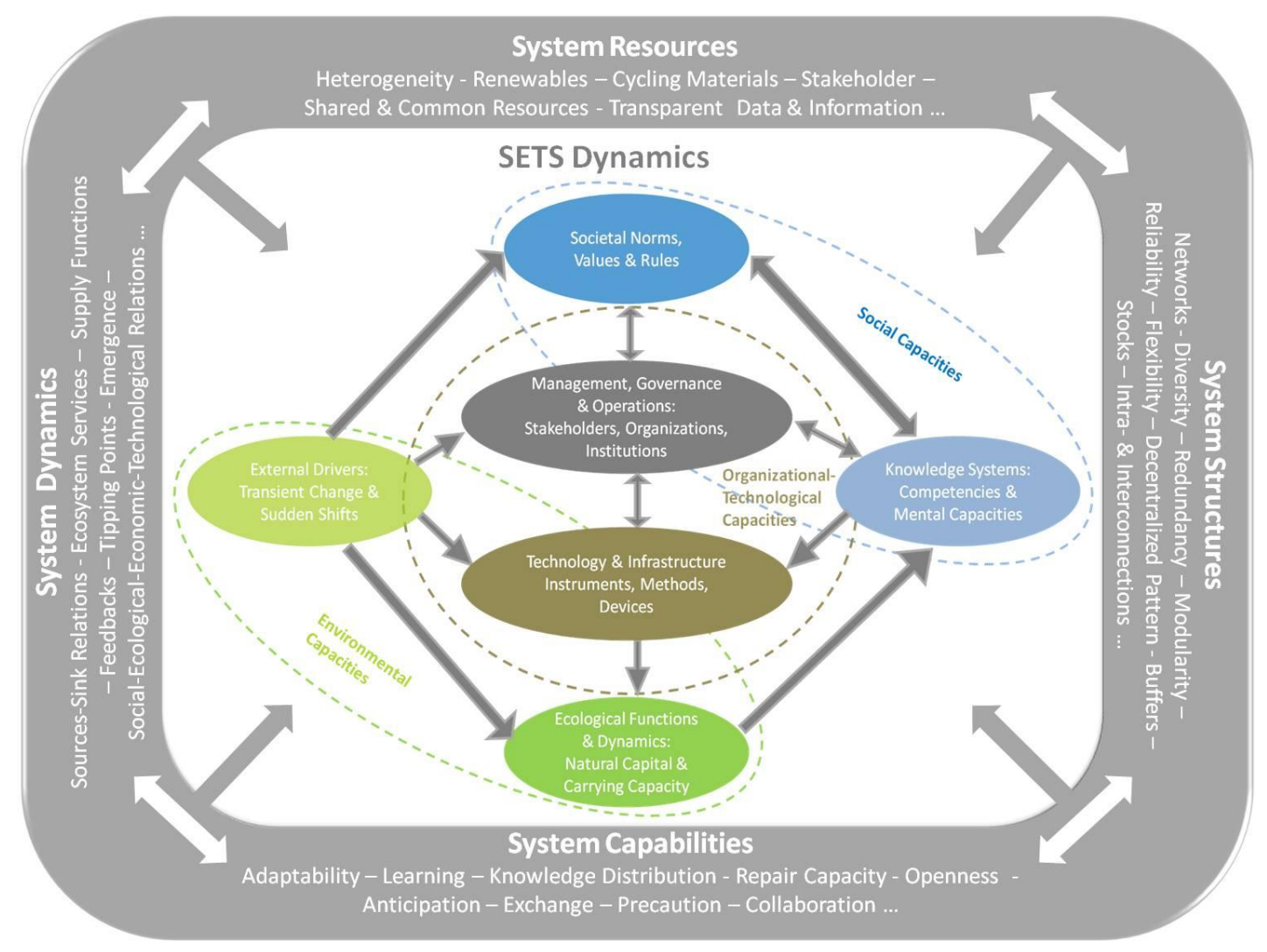

Fig .8. Conceptual Model of Resilience Design Dimensions and SETS Dynamics (own conceptualization with reference to Walker, Holling et al. 2004, Hahn, Schultz et al. 2008) 
An exemplification on the earlier mentioned importance of post-fossil energy system conversion may initially reveal resilience driven system design options out of this model:

We can exemplify both external and internal design opportunities from the above explanations. Post-fossil renewable energy networks are driven by a consensus on minimizing negative impacts on the natural capital base and limiting socio-economic actions below thresholds within ecological carrying capacities (to assimilate impacts and/or to avoid negative feedbacks, transient shifts or sudden shocks to the socio-economic system). It also integrates ecological services and natural cycles of ecosystem productivity in energy harvesting, while keeping a functional balance between natural productivity and consumption rates. Besides working on infrastructure and spatial pattern (a heterogeneity of green renewable energy sources, infrastructural facilities and energy transport modes, electricity networks and smart grids, energy storage facilities, interactive consumption sub-systems, intelligent energy efficient devices at the consumption side), resilience design may also affect the relationships within the system and influence embeddedness of elements into higher and lower levels of a nested hierarchy organization. This would touch upon concrete hierarchy levels of planning and of operating the networks (levels of complex systems operations management, participatory network designs in decentralized pattern and local, regional (semi-) autarky of closed energy production and supply systems). It would also mean that a sustainable energy transition represents some paramount questions of the institutional and "bottom up" stakeholder frameworks, taking into account that knowledge of sustainability issues and a directed competence and capacity building, empowerment and awareness raising (incorporating all stakeholder groups) would not only increase the quality of results. It would also improve their ability to survive and flourish and also their ability to flexibly modify intermediate results in an iterative manner and to produce continuous improvement and innovation in terms of adaptive management.

\section{CONCLUSION AND OUTLOOK}

The article took up the complex and dynamic system nature of the sustainability challenge and transferred problems into a system based reception of both unsustainability and sustainability. It has been made clear that truly effective countermeasures necessitate a system thinking approach. Nested systems organization provides not only a structuring of problems in terms of drivers, effects, feedbacks and complex interrelationships. They also ask for principles how systems are able to cope with existential disturbances and stresses through complex and dynamic interplays of system compartments with differentiated feedbacks in multiple equilibriums of the affected system while upholding the essential functions and structures to fulfil the general purpose of the system, defined as resilience. A resilience guided design of socio-economic sub-systems and their interconnected ecological sub-systems applied in a holistic frame is favoured as a concrete orientation for more deeply understood sustainability strategies. It was furthermore demonstrated that for the purpose of sustainable systems, social networks and their organizations/ institutions play a decisive role for success or failure in our efforts towards sustainability. Based on four categories of resilience design system properties two central strands of conceptual improvement could be discerned:

- Systems integration based on source-sink and respectively supply-demand rationales with setting advanced inclusive system boundaries towards centrally important urban-industrial systems. The result encompasses and systematizes the relevant key performance factors for a sustainable operations framework of an urban-industrial nexus as an advanced ecological urban-industrial metabolism model and introduces functional domains as new conceptual term into the sustainability discourse.

- Advancement of SES to SETS as guiding framework to concretize a newly contextualized role of technology together with other driving forces within dynamics for sustainable development, especially in heavily transformed artificial environments such as urban-industrial systems. Dynamics of SETS could be brought together on a platform of four resilience design system properties, namely: resources, structures, capabilities and dynamics.

As a future direction for further elaborations the synthesis of the urban-industrial nexus (resources and structures in new integrative boundaries) with SETS as an advanced framework (additionally considering capabilities and dynamics) can formulate new impulses for transition actions in the frame of 
sustainable development. Such frameworks can help:

- Understanding of sustainable or unsustainable systems by providing a more complete and realistic picture on dynamics

- Guiding and structuring of planning and management for alternative systems or system alternatives

- Making urban-industrial systems, their governance structures and their transition pathways comparable

- Supporting sustainable socio-economic transitions, and

- Determining future needs for research.

Hence, learning and capacity building play an imperative role for resilience, the co-production of science with the public sector, business and civic organizations are needed to successfully implement new developments. For science stakeholders, this bears two resilience specific meanings: to better understand needs and options for sustainable solutions through transition research and to take part as a promoter of sustainable development based on a specifically academic competence and through exploring new trans-disciplinary methodological settings and experimental innovation designs as transformative research. Combining transition research with transformative research will accentuate a new role of post-normal science without which the desired development will not take place (Wiek, Farioli et al. 2012, Miller, Wiek et al. 2014).

A ground for such integrative research and transition settings is contributed by Evans (2011) relating experimental cities with a system approach and resilience design. A combination with a strong system dynamics based ecosystem approach (Kay, Regier et al. 1999, Newman 1999, Newman and Jennings 2012) would broaden the experimental city towards the here proposed urban-industrial system boundaries as innovative coordinates for sustainable development.

This should be taken as a strong motivation to further enhance the exchange between sustainability oriented academic disciplines together with stakeholders from business, policy and the civil society in appropriate work interfaces and platforms under a suggested stronger systems integration and with this to substantially contribute to resilience of social, economic and ecological dimensions of the planetary system as a whole.

\section{REFERENCES}

[1] J. Ahern. "From fail-safe to safe-to-fail: Sustainability and resilience in the new urban world." Landscape and Urban Planning, vol. 100(4), pp. 341-343, 2011.

[2] J. Ahern. "Urban landscape sustainability and resilience: The promise and challenges of integrating ecology with urban planning and design." Landscape Ecology, 28(6), pp. 12031212, 2012.

[3] J. Ahern, S. Cilliers and J. Niemelä. "The concept of ecosystem services in adaptive urban planning and design: A framework for supporting innovation." Landscape and Urban Planning, vol. 125, pp. 254-259, 2014.

[4] B. Alder. "Silent revolution in research for sustainability." Renewable Energy and Sustainable Development, vol. 2(1), pp. 2-3, 2014.

[5] A. Atkinson. "Cities after oil-1:'Sustainable development'and energy futures." Cities, vol. 11(2), pp. 201-213, 2007.

[6] R. Ayres, J. van den Berrgh and J. Gowdy. "Strong versus weak sustainability." Environmental Ethics, vol. 23(2), pp. 155-168, 2001.

[7] A. Bahadur, V., M. Ibrahim and T. Tanner. "Characterising resilience: unpacking the concept for tackling climate change and development." Climate and Development, vol. 5(1), pp. 55-65, 2013.

[8] R. Barkemeyer, D. Holt, L. Preuss and S. Tsang. "What happened to the 'development'in sustainable development? Business guidelines two decades after Brundtland." Sustainable Development, vol. 22(1), pp. 15-32, 2014. 
[9] A. D. Barnosky, E. A. Hadly, J. Bascompte, E. L. Berlow, J. H. Brown, M. Fortelius, W. M. Getz, J. Harte, A. Hastings and P. A. Marquet. "Approaching a state shift in Earth's biosphere." Nature, vol. 486(7401), pp. 52-58, 2012.

[10] S. Beer. "The viable system model: Its provenance, development, methodology and pathology." Journal of the Operational Research Society,vol. 35(1), pp. 7-25, 1984.

[11] L. Bertalanffy. "An outline of general system theory." British Journal for the Philosophy of Science,vol. 1(2), pp. 134-165, 1950.

[12] L. Bertalanffy. General Systems Theory Foundations, Development, Applications. New York: George Braziller, 1968

[13] C. R. Binder, I. Absenger-Helmli and T. Schilling. "The reality of transdisciplinarity: a framework-based self-reflection from science and practice leaders." Sustainability Science, vol. 10(4), pp. 545-562, 2015.

[14] H. Bossel. "Viability and sustainability: Matching development goals to resource constraints." Futures, vol. 19(2), PP. 114-128, 1987.

[15] H. Bossel. Systems and models: complexity, dynamics, evolution, sustainability. BoD-Books on Demand. 2007.

[16] E.D. Brown and B. K. Williams. "Resilience and Resource Management." Environmental Management, vol. 56(6), pp. 1416-1427, 2015.

[17] G. Brundtland, M. Khalid, S. Agnelli, S. AlAthel, B. Chidzero, L. Fadika, V. Hauff, I. Lang, M. Shijun and M. M. de Botero. Our Common Future, The World Comission on Environment and Development, New York: Oxford University Press, 1987.

[18] G. Bugliarello. "Urban sustainability: Dilemmas, challenges and paradigms." Technology in Society, vol. 28(1-2), pp. 19-26, 2006.

[19] S. Chopra and V. Khanna. "Understanding resilience in industrial symbiosis networks: insights from network analysis." Journal of Environmental Management, vol. 141, pp. 8694, 2014.
[20] W.C. Clark and N. M. Dickson. "Sustainability Science: The emerging research program." Proceedings of the National Academy of Sciences, vol. 100(14), pp. 8059-8061, 2003.

[21] H. M. Cooper. Integrating research: A guide for literature reviews. New York: Sage Publications, 1989.

[22] H. M. Cooper. Synthesizing research: A guide for literature reviews. New York: Sage Publications, 1998.

[23] R. Costanza, R. d'Arge, R. de Groot, S. Farberk, M. Grasso, B. Hannon, K. Limburg, S. Naeem, R. V. O'Neill and J. Paruelo. "The value of the world's ecosystem services and natural capital." NATURE, vol. 387, pp. 253, 1997.

[24] R. Costanza, H. E. Daly and J. A. Bartholomew. "Goals, agenda and policy recommendations for ecological economics." Environmental Accounting for Sustainable Development, vol. 3, pp. 1-12, 1992.

[25] R. Costanza and B. C. Patten. "Defining and predicting sustainability." Ecological Economics, vol. 15(3), pp. 193-196, 1995.

[26] M. Cote and A. J. Nightingale. "Resilience thinking meets social theory situating social change in socio-ecological systems (SES) research." Progress in Human Geography, vol. 36(4), pp. 475-489, 2012.

[27] A.T.C.J. Dangerman and H. J. Schellnhuber. "Energy systems transformation." Proceedings of the National Academy of Sciences, vol. 110(7), pp. E549-E558, 2013.

[28] G. R. Davies. "Appraising weak and strong sustainability: searching for a middle ground." Consilience: The Journal of Sustainable Development, vol. 10(1), pp. 111-124, 2013.

[29] R.S. de Groot, R. Alkemade, L. Braat, L. Hein and L. Willemen. "Challenges in integrating the concept of ecosystem services and values in landscape planning, management and decision making." Ecological Complexity, vol. 7(3), pp. 260-272, 2010. 
[30] R. S. de Groot, M. A. Wilson and R. M. Boumans. "A typology for the classification, description and valuation of ecosystem functions, goods and services." Ecological economics, vol. 41(3), pp. 393-408, 2002.

[31] B. J. De Vries, D. P. Van Vuuren and M. M. Hoogwijk. "Renewable energy sources: Their global potential for the first-half of the $21 \mathrm{st}$ century at a global level: An integrated approach." Energy Policy, vol. 35(4), pp. 25902610, 2007.

[32] S. Derissen, M. F. Quaas and S. Baumgärtner. "The relationship between resilience and sustainability of ecological-economic systems." Ecological Economics, vol. 70(6), pp. 11211128, 2011.

[33] G. DeSanctis and M. S. Poole. "Capturing the complexity in advanced technology use: Adaptive structuration theory." Organization Science, vol. 5(2), pp. 121-147, 1994.

[34] P. Deutz and G. loppolo. "From theory to practice: Enhancing the potential policy impact of industrial ecology." Sustainability, vol. 7(2), pp. 2259-2273, 2015.

[35] S. Dietz and E. Neumayer. "Weak and strong sustainability in the SEEA: Concepts and measurement." Ecological Economics, vol. 61(4), pp. 617-626, 2007.

[36] M. Earl. "Knowledge management strategies: Toward a taxonomy." Journal of Management Information Systems, vol. 18(1), pp. 215-233, 2001.

[37] P. Ekins, S. Simon, L. Deutsch, C. Folke and R. De Groot. "A framework for the practical application of the concepts of critical natural capital and strong sustainability." Ecological Economics, vol. 44(2-3), pp. 165-185, 2003.

[38] J. Elkington. Cannibals with forks The triple bottom line of 21 st century business. Oxford: Capstone Publishing, 1997

[39] J.P. Evans. "Resilience, ecology and adaptation in the experimental city." Transactions of the
Institute of British Geographers, vol. 36(2), pp. 223-237, 2011.

[40] J. Fiksel. "Sustainability and resilience: toward a systems approach", IEEE Engineering Management Review, vol. 3(35), p. 5, 2007.

[41] J. Fiksel. Design for Resilience - Resilient by Design: Creating Businesses that adapt and flourish in a Changing World. Washington, DC, Island Press/Center for Resource Economics, pp. 173-189, 2015

[42] C. Folke. "Resilience: The emergence of a perspective for social-ecological systems analyses." Global environmental change, vol. 16(3), pp. 253-267, 2006.

[43] C. Folke, S. Carpenter, T. Elmqvist, L. Gunderson, C. S. Holling and B. Walker. "Resilience and sustainable development: building adaptive capacity in a world of transformations." Ambio, vol. 31(5), pp. 437440, 2002.

[44] C. Folke, S. R. Carpenter, B. Walker, M. Scheffer, T. Chapin and J. Rockstrom. "Resilience thinking: integrating resilience, adaptability and transformability", Ecology and Society, vol. 15(4), p. 20, 2010

[45] C. Folke and J. Rockström. "Turbulent times." Global Environmental Change, vol. 19(1), pp. 13, 2010.

[46] J.W. Forrester. Industrial Dynamics. Cambridge: MIT Press, 1961.

[47] J.W. Forrester. Urban Dynamics. Cambridge: MIT Press, 1969.

[48] J.W. Forrester. "Industrial Dynamics." Journal of the Operational Research Society, vol. 48(10), pp. 1037-1041, 1997.

[49] S. Funtowicz and J. Ravetz. "Post-normal science." International Society for Ecological Economics (ed.), Online Encyclopedia of Ecological Economics [online]. Available: http://www. ecoeco. org/publica/encyc. htm, 2003

[50] S. Funtowicz and J. R. Ravetz. Science for the 
post normal age. New York: Springer, 1995.

[51] R.A. Galil. "Sustainability and energy selfsufficiency; overcoming the barriers." Renewable Energy and Sustainable Development, vol. 1(2), pp. 230-231, 2015.

[52] N. Georgescu-Roegen. "Energy and economic myths." Southern Economic Journal, vol. 41(3), pp. 347-381, 1975.

[53] N. Georgescu-Roegen. The entropy law and the economic problem.In: H. Daly and K. Townsend. Valuing the earth: Economics, ecology, ethics. Cambridge: MIT Press, pp. 75-88. 1996

[54] H. Girardet. Cities and the Culture of Sustainability.In: F. Dodds and T. Middleton (eds.). Earth Summit 2002 - A New Deal. New York: Routledge, pp. 203-211, 2000.

[55] L.H. Gunderson. "Ecological resilience in theory and application." Annual review of ecology and systematics:, vol. 31, pp. 425-439, 2000.

[56] T. Hahn, L. Schultz, C. Folke and P. Olsson. Social networks as sources of resilience in social-ecological systems. In: J. Norberg and G.S. Cumming. Complexity theory for a sustainable future. New York: Columbia University Press, pp. 119-148, 2008.

[57] R.B. Handfield and S. A. Melnyk. "The scientific theory-building process: a primer using the case of TQM." Journal of Operations Management , vol. 16(4), pp. 321-339, 1998.

[58] R. Heinberg. Powerdown: Options and actions for a post-carbon world. Gabriola Island: New Society Publishers, 2004.

[59] A.Y. Hoekstra and T. O. Wiedmann. "Humanity's unsustainable environmental footprint." Science, vol. 344(6188), pp. 1114-1117, 2014.

[60] C.S. Holling. "Resilience and stability of ecological systems." Annual review of ecology and systematics, vol. 4(1), pp. 1-23, 1973.

[61] H.J. Hsia. Mass communications research methods: A step-by-step approach. London: Routledge, 2015.
[62] T.P. Hughes, S. Carpenter, J. Rockström, M. Scheffer and B. Walker. "Multiscale regime shifts and planetary boundaries." Trends in Ecology \& Evolution, vol. 28(7), pp. 389-395, 2013.

[63] M. Jänicke. "Green growth: From a growing ecoindustry to economic sustainability." Energy Policy, vol. 48, pp. 13-21, 2012.

[64] Y. Kajikawa. "Research core and framework of sustainability science." Sustainability Science, vol. 3(2), pp. 215-239, 2008.

[65] J.J. Kay, H. A. Regier, M. Boyle and G. Francis. "An ecosystem approach for sustainability: addressing the challenge of complexity." Futures, vol. 31(7), pp. 721-742, 1999.

[66] K. Kaygusuz. "Energy for sustainable development: A case of developing countries." Renewable and Sustainable Energy Reviews , vol. 16(2), pp. 1116-1126, 2012.

[67] L. Kerkhoff. "Developing integrative research for sustainability science through a complexity principles-based approach." Sustainability Science, vol. 9(2), pp. 143-155, 2013.

[68] A. Kläy , A. B. Zimmermann and F. Schneider. "Rethinking science for sustainable development: Reflexive interaction for a paradigm transformation." Futures, vol. 65, pp. 72-85, 2015.

[69] J. Korhonen and T. P. Seager. "Beyond eco-efficiency: a resilience perspective." Business Strategy and the Environment, vol. 17(7), pp. 411-419, 2008.

[70] J. Korhonen and J.-P. Snäkin. "Quantifying the relationship of resilience and eco-efficiency in complex adaptive energy systems." Ecological Economics, vol. 120, pp. 83-92, 2015.

[71] K. Krumme. "EFU - Ecological Functional Units: A Basis for Sustainable Development Planning." FWU Water Resources Publications, vol. 5(Participatory Watershed Management Plan), pp. $17-28,2006$.

[72] K. Krumme. "Why smart is not enough - system ecology and strong sustainability as conceptual 
drivers for experimental cities: Options for an integrated framework on urban transition management. Working Paper, University of Duisburg-Essen, 2016

[73] R. J. Lawrence. "Advances in transdisciplinarity: Epistemologies, methodologies and processes." Futures, vol. 65, pp. 1-9, 2015.

[74] J. Liu, H. Mooney, V. Hull, S. J. Davis, J. Gaskell, T. Hertel, J. Lubchenco, K. C. Seto, P. Gleick, C. Kremen and S. Li "Sustainability. Systems integration for global sustainability." Science, vol. 347(6225), pp. 1258832, 2015.

[75] V. Marchal, R. Dellink, D. van Vuuren, C. Clapp, J. Chateau, B. Magné and J. van Vliet. OECD environmental outlook to 2050. Organization for Economic Co-operation and Development (OECD). 2011

[76] M. D. McGinnis and E. Ostrom. "SocialEcological System framework: Initial changes and continuing challenges." Ecology and Society, vol. 19(2), p. 30, 2014

[77] T. McPhearson, S. T. A. Pickett, N. B. Grimm, J. Niemelä, M. Alberti, T. Elmqvist, C. Weber, D. Haase, J. Breuste and S. Qureshi. "Advancing Urban Ecology toward a Science of Cities." BioScience, vol. 66(3), pp. 198-212, 2016.

[78] J. Meredith. "Theory building through conceptual methods." International Journal of Operations \& Production Management, vol. 13(5), pp. 3-11, 1993.

[79] T.R. Miller, A. Wiek, D. Sarewitz, J. Robinson, L. Olsson, D. Kriebel and D. Loorbach. "The future of sustainability science: a solutions-oriented research agenda." Sustainability Science, vol. 9(2), pp. 239-246, 2014.

[80] S.O. Negro, F. Alkemade and M. P. Hekkert. "Why does renewable energy diffuse so slowly? A review of innovation system problems." Renewable and Sustainable Energy Reviews, vol. 16(6), pp. 3836-3846, 2012.

[81] E. Neumayer. Weak Versus Strong Sustainability: Exploring the Limits of Two Opposing Paradigms. Northhampton
Massachusetts: Edward Elgar Publishing, 2003.

[82] E. Neumayer. "Human development and sustainability." Journal of Human Development and Capabilities, vol. 13(4), pp. 561-579, 2012.

[83] P. Newman and I. Jennings. Cities as Sustainable Ecosystems: Principles and Practices. Washington DC: Island Press, 2012.

[84] P. Newman. "Sustainability and cities: extending the metabolism model." Landscape and Urban Planning, vol. 44(4), pp. 219-226, 1999.

[85] E.P. Odum. and G. W. Barrett. Fundamentals of Ecology. Philadelphia: Saunders, 1971.

[86] E. Ostrom. "A diagnostic approach for going beyond panaceas." Proceedings of the National Academy of Sciences, vol. 104(39), pp. 1518115187, 2007.

[87] E. Ostrom, E. "A General Framework for Analyzing Sustainability of Social-Ecological Systems." Science, vol. 325(5939), pp. 419422, 2009.

[88] P.D. Panagiotakopoulos, A. Espinosa and J. Walker. "Sustainability management: insights from the Viable System Model." Journal of Cleaner Production, vol. 113: 792-806, 2016.

[89] C. Perrings and B. Walker. "Conservation in the optimal use of rangelands." Ecological Economics, vol. 49(2), pp. 119-128, 2204.

[90] D.J. Rapport. Ecosystem Health: An Emerging Integrative Science. New York: Springer, 1995.

[91] J.R. Ravetz. "Usable knowledge, usable ignorance incomplete science with policy implications." Science Communication, vol. 9(1), pp. 87-116, 1987.

[92] J.R. Ravetz. "Post-normal science and the complexity of transitions towards sustainability." Ecological Complexity, vol. 3(4), pp. 275-284, 2006.

[93] W.E. Rees and M. Wackernagel. "Urban ecological footprints: Why cities cannot be sustainable-and why they are a key to 
sustainability." Environmental Impact Assessment Review, vol. 16(4-6), pp. 223-248, 1996.

[94] W.E. Rees. "Is 'sustainable city'an oxymoron?" Local environment, vol. 2(3), pp. 303-310, 1997.

[95] W.E. Rees. Global Change, Ecologiocal Footprints, and Urban Sustainability. In: D. Devuyst, L. Hens, W. De Lannoy. How Green is the City? Sustainability Assessment and the Management of Urban Environments: p. 339, 2001.

[96] W.E. Rees. Understanding urban ecosystems: an ecological economics perspective. In: A. Berkowitz, C. Nilon and K. Hollweg (eds.). Understanding Urban Ecosystems. New York: Springer, pp. 115-136. 2003

[97] J. Rockstrom and M. Klum. Big World, Small Planet: Abundance Within Planetary Boundaries. New Haven: Yale University Press, 2015.

[98] J. Rockström, W. Steffen, K. Noone, Å. Persson, F. S. Chapin, E. F. Lambin, T. M. Lenton, M. Scheffer, C. Folke and H. J. Schellnhuber. "A safe operating space for humanity." Nature, vol. 461(7263), pp. 472-475, 2209.

[99] J.D. Sachs. "From millennium development goals to sustainable development goals." The Lancet, vol. 379(9832), pp. 2206-2211, 2012.

[100] J.D. Sachs. "Achieving the sustainable development goals." Journal of International Business Ethics, vol. 8(2) , pp. 53, 2015.

[101] J.D. Sachs. The World in 2050 - Towards Sustainable Development and Deep Decarbonization, Mercator Climate Lecture 2016. Technical University Berlin, Mercator Foundation. 2016

[102] H.J. Schellnhuber and M. A. Martin. ClimateSystem Tipping Points and Extreme Weather Events. Pontifical Academy of Sciences and Pontifical Academy of Social Sciences: Sustainable Humanity, Sustainable Nature: Our Responsibility, 2014.

[103] P. Senge. The fifth discipline: The art and science of the learning organization. London:
Random House, 1990

[104] K.C. Seto and D. Satterthwaite. "Interactions between urbanization and global environmental change." Current Opinion in Environmental Sustainability, vol. 2(3), pp. 127-128, 2010.

[105] P. Shrivastava. "The role of corporations in achieving ecological sustainability." Academy of Management Review, vol. 20(4) , pp. 936-960, 1995.

[106] W. Steffen, K. Richardson, J. Rockström, S. E. Cornell, I. Fetzer, E. M. Bennett, R. Biggs, S. R. Carpenter, W. de Vries and C. A. de Wit. "Planetary boundaries: Guiding human development on a changing planet." Science, vol. 347(6223), pp. 1259855, 2015.

[107] W. Steffen, K. Richardson, J. Rockstrom, S. E. Cornell, I. Fetzer, E. M. Bennett, R. Biggs, S. R. Carpenter, W. de Vries, C. A. de Wit, C. Folke, D. Gerten, J. Heinke, G. M. Mace, L. M. Persson, V. Ramanathan, B. Reyers and S. Sorlin. "Sustainability and planetary boundaries: guiding human development on a changing planet." Science, vol. 347(6223) , pp. 1259855, 2015.

[108] J.D. Sterman. Business Dynamics: Systems Thinking and Modeling for a Complex World. New York: McGraw-Hill Higher Education, 2000

[109] D.S. Thomasand C. Twyman. "Equity and justice in climate change adaptation amongst natural-resource-dependent societies." Global Environmental Change, vol. 15(2), pp, 115124, 2005.

[110] F. Tonelli, S. Evans and P. Taticchi. "Industrial sustainability: challenges, perspectives, actions." International Journal of Business Innovation and Research, vol. 7(2), pp. 143163, 2013.

[111] J. Twidelland T. Weir. Renewable Energy Resources. London: Routledge, 2015.

[112] UNISDR. Disaster risk and resilience. Thematic Think Piece, UN System Task Force on the Post-2015 UN Development Agenda. 2012

[113] United Nations. Sustainable Development Goals. New York, 2015. 
[114] J.G. Wacker. "A conceptual understanding of requirements for theory-building research: Guidelines for scientific theory building." Journal of Supply Chain Management, vol. 44(3) , pp. 5-15, 2008.

[115] M. Wackernagel, J. Kitzes, D. Moran, S. Goldfinger and M. Thomas. "The ecological footprint of cities and regions: Comparing resource availability with resource demand." Environment and Urbanization, vol. 18(1), pp. 103-112, 2006.

[116] B. Walker , L. Gunderson, A. Kinzig, C. Folke, S. Carpenter and L. Schultz. "A handful of heuristics and some propositions for understanding resilience in social-ecological systems.", Ecology and Society, vol. 11(1), p. 13, 2006.

[117] B. Walker , C. S. Holling, S. R. Carpenter and A. Kinzig. "Resilience, adaptability and transformability in social-ecological systems." Ecology and Society, vol. 9(2), pp. 5, 2004.

[118] G. Whiteman, B. Walker and P. Perego. "Planetary boundaries: Ecological foundations for corporate sustainability." Journal of Management Studies, vol. 50(2), pp. 307336, 2013.
[119] T. Wiedmann, J. Minx, J. Barrett and M. Wackernagel. "Allocating ecological footprints to final consumption categories with inputoutput analysis." Ecological Economics, vol. 56(1) , pp. 28-48, 2006.

[120] Wiek, F. Farioli, K. Fukushi and M. Yarime. "Sustainability science: bridging the gap between science and society." Sustainability Science, vol. 7(1), pp. 1-4, 2012.

[121] Wilkinson, P. Horwitz, S. Bahn, J. Redmond and J. Dooley. "Sustainability and action research in universities." International Journal of Sustainability in Higher Education, vol. 16(4) , pp. 424-439, 2015.

[122] L. Xu, L., D. Marinova and X. Guo. "Resilience thinking: a renewed system approach for sustainability science." Sustainability Science, vol. 10(1), pp. 123138, 2014.

[123] J. Zhu and M. Ruth. "Exploring the resilience of industrial ecosystems." Journal of Environmental Management, vol. 122, pp. 65-75, 2013. 